\title{
Intra-radicular dentin treatments and retention of fiber posts with self- adhesive resin cements
}

\begin{abstract}
André Luis Faria-e-Silva(a) Murilo de Sousa Menezes(b) Fernanda Pereira Silva ${ }^{(b)}$ Giselle Rodrigues dos Reis ${ }^{(b)}$ Rafael Ratto de Moraes(c)
\end{abstract}

\footnotetext{
(a) Department of Dentistry, School of Dentistry, Univ Federal de Sergipe - UFS, Aracaju, SE, Brazil.
}

(b) Department of Restorative Dentistry and Dental Materials, School of Dentistry, Univ Federal de Uberlândia - UFU, Uberlândia, MG, Brazil.

(c) Department of Restorative Dentistry, School of Dentistry, Univ Federal de Pelotas UFPel, Pelotas, RS, Brazil.

\begin{abstract}
The aim of this study was to evaluate the effect of treating intraradicular dentin with irrigating solutions on the retention of glassfiber posts luted with self-adhesive resin cement. Bovine incisors were endodontically treated, and 9-mm-deep postholes were prepared. Before inserting the cement, the root canals were irrigated with various solutions: $11.5 \%$ polyacrylic acid for $30 \mathrm{~s}, 17 \%$ EDTA for $60 \mathrm{~s}$, or $5 \%$ $\mathrm{NaOCl}$ for $60 \mathrm{~s}$, respectively. Irrigation with distilled water was used in the control group. After all specimens had been rinsed with distilled water, the excess moisture was removed and the posts were luted using either BisCem (Bisco) or RelyX Unicem clicker (3M ESPE). Seven days after luting, the specimens were sectioned transversally into 1-mm-thick slices, which were submitted to push-out testing on a mechanical testing machine. Bond strength data ( $\mathrm{n}=6$ per group) were analyzed by twoway ANOVA and Student-Newman-Keuls' test $(\alpha=0.05)$. For Unicem, EDTA showed lower bond strength than the other solutions, which had similar results. For BisCem, EDTA showed higher bond strength than the other treatments, while application of $\mathrm{NaOCl}$ yielded higher bond strength than polyacrylic acid whereas the control group had intermediate results. In conclusion, irrigating root canals before insertion of selfadhesive resin cements, especially EDTA, might interfere with retention of the fiber posts.
\end{abstract}

Descriptors: Dental Bonding; Post and Core Technique; Resin Cement; Smear Layer.

\section{Introduction}

Glass-fiber posts are widely used to restore endodontically treated teeth when the remaining tooth structure cannot provide adequate support and retention for the restoration. ${ }^{1}$ The similar elastic modulus of fiber posts and dentin is considered advantageous for restoring endodontically treated teeth; the risk of root fracture is reduced, and failures, when they occur, tend not to be severe. ${ }^{2,3}$ Post debonding is one of the possible failures, caused by the complexity of bonding to root canals. ${ }^{4,5}$ Inadequate adhesion, which may result from the multiple-step procedures required for post bonding, interferes with the ability of luting materials to retain the post. ${ }^{4}$ Simplified luting agents, in such a context, are gaining increased popularity. ${ }^{6}$

Self-adhesive resin cements (SARCs) have been marketed to simpli-
Submitted: Aug 20, 2012

Accepted for publication: Oct 26, 2012

Last revision: Oct 26, 2012 
fy clinical procedures and overcome the technique sensitivity of multiple-step systems. According to manufacturers, SARCs do not require any pretreatment of the dental surfaces, their application being accomplished using a single clinical step. The main adhesive of SARCs is attributed to a chemical reaction between phosphate methacrylates and hydroxyapatite $;^{7,8}$ these cements present limited infiltration into the tooth tissues. 9 Previous studies, however, have reported low bond strength of SARCs to dentin due to the limited ability of these materials to properly etch tooth substrates. ${ }^{10,11}$ Thus, investigators have proposed dentin pretreatments to aid in removing the smear layer created in the coronal dentin and to improve interaction with SARCs. These studies report conflicting findings; $;^{12-14}$ in addition, results for coronal dentin cannot be easily extrapolated to intraradicular dentin.

During endodontic treatment, mineralized tissues are shattered, producing considerable quantities of mineral debris and generating a smear layer on the root canal walls. ${ }^{15}$ The smear layer produced in the root canal is thicker and denser that that observed in coronal dentin. The presence of such a layer impairs a proper contact between the acidic methacrylates of SARCs and the underlying dentin during adhesive procedures, interfering with its bond strength to dentin. Thus, partial or total removal of the smear layer previous to insertion of the SARCs into root canals might improve post retention. A previous study has shown that post-space irrigation partially removes the smear layer and might improve the bond strength of fiber posts luted with a resin cement associated with self-etching bonding agents. ${ }^{16}$ However, it is not known whether the same effect would occur for self-adhesive resin cements.

The aim of this study was to evaluate the effect of treating intraradicular dentin with irrigating solutions on the retention of fiber posts luted into root canals using SARCs. The hypothesis was that post retention would not be improved by treating the dentin surfaces before luting.

\section{Methodology}

The crowns of bovine incisors with mature apices and straight roots were removed to standard- ize a $14-\mathrm{mm}$ root length. Roots having canals with larger diameters than the drill of the post kit were discarded. In total, 48 roots were used in the study. For the endodontic treatment, a step-back preparation technique was used with stainless steel K-files and Nos. 2 to 4 Gates-Glidden drills. All enlargement procedures were carried out under irrigation with $2.5 \% \mathrm{NaOCl}$ solution. The prepared root canals were filled with gutta-percha cones and resin sealer (Sealer-26; Dentsply Caulk, Milford, USA) by the lateral condensation technique. The filled roots were stored in $100 \%$ relative humidity for $72 \mathrm{~h}$ so the resin sealer could set.

A glass fiber-reinforced epoxy post system (White Post DC3; FGM, Joinville, Brazil) was used. Postholes were prepared with 9-mm drills available in the post kit. The post surfaces were etched by immersion in $24 \% \mathrm{H}_{2} \mathrm{O}_{2}$ for $10 \mathrm{~min}$ and silanated. Four different intraradicular dentin treatments (irrigation solutions) were tested:

- (1) $11.5 \%$ polyacrylic acid for $30 \mathrm{~s}$,

- (2) $17 \%$ ethylenediaminetetraacetic acid (EDTA) for $60 \mathrm{~s}$,

- (3) $5 \% \mathrm{NaOCl}$ for $60 \mathrm{~s}$, and

- (4) none (control).

Nos. 2 and 3 were based on previous studies of endodontic protocols used to remove the smear layer before filling, ${ }^{12}$ while polyacrylic acid (No.1) is commonly used to remove the smear layer previous to inserting the glass ionomer. After application of the irrigating solutions, the root canals were rinsed with distilled water and excess moisture was removed with absorbent paper points.

Two SARCs were tested:

- RelyX Unicem clicker (3M ESPE, St Paul, USA) and

- BisCem (Bisco, Schaumburg, USA).

Composition of the materials is shown in Table 1. The cements were mixed for $10 \mathrm{~s}$ and inserted into the root canals using a Centrix syringe. The posts were inserted with light hand pressure and excess luting material was removed. Light activation was performed through the cervical portion of the root for $40 \mathrm{~s}$, on both the buccal and lingual sur- 

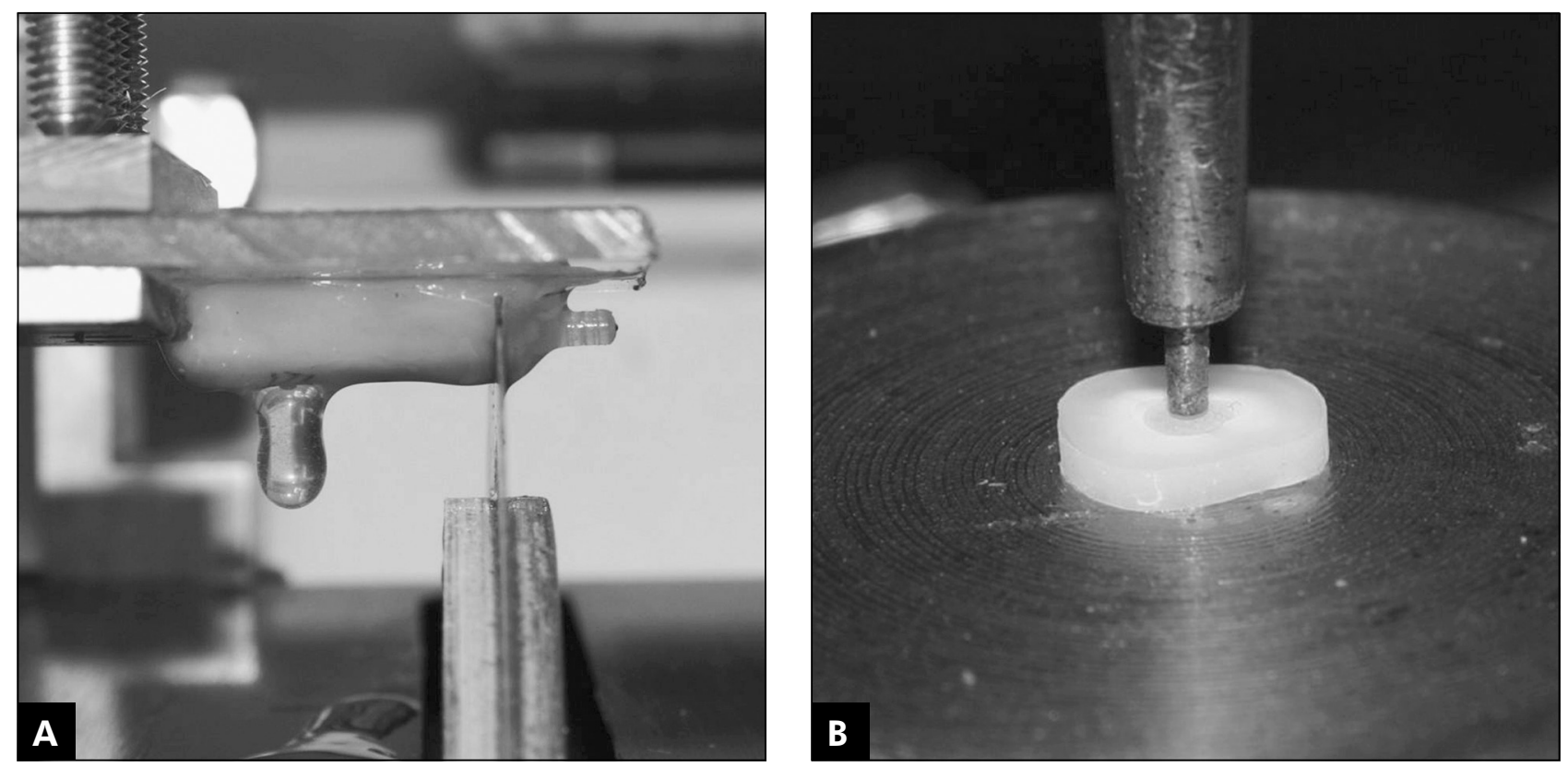

Figure 1 - A: sectioning of the roots with the fiber posts luted into the canals; B: sectioned specimen positioned in the mechanical testing machine for the push-out test.

Table 1 - Composition of the self-adhesive resin cements tested.

\begin{tabular}{l|l}
\hline Material & Main components* \\
\hline BisCem & $\begin{array}{l}\text { Base: bisphenol-A glycidyl dimethacrylate, uncured } \\
\text { dimethacrylate monomer, glass filler } \\
\text { Catalyst: phosphate acidic monomer, glass fillers }\end{array}$ \\
\hline Unicem & $\begin{array}{l}\text { Base: } \text { methacrylate monomers containing acid } \\
\text { groups, methacrylate monomers, silanated fillers, } \\
\text { initiator components, stabilizer } \\
\text { Catalyst: methacrylate monomer, alkaline fillers, } \\
\text { silanated fillers, initiator components }\end{array}$ \\
\hline
\end{tabular}

${ }^{*}$ As provided by the manufacturers.

faces, using a light-emitting diode curing unit (Radii Cal; SDI, Bayswater, Victoria, Australia) with 600$\mathrm{mW} / \mathrm{cm}^{2}$ irradiance.

After storage in distilled water at $37^{\circ} \mathrm{C}$ for 1 week, the roots were sectioned into six 1-mm-thick slabs (Figure 1A). The slabs were positioned on a push-out jig in a mechanical testing machine (model 4411; Instron, Canton, USA; Figure 1B). The load was applied at a crosshead speed of $0.5 \mathrm{~mm} / \mathrm{min}$ until the post was dislodged. The bond strength value for each slab was calculated in MPa, and the average values of all slabs for each root were used in the statistical analysis ( $\mathrm{n}=6$ per group). Data were analyzed by two-way ANOVA (dentin treatment $\times$ ma-
Table 2 - Means (standard deviations) for push-out bond strength, in $\mathrm{MPa}$.

\begin{tabular}{c|c|c}
\hline \multirow{2}{*}{ Irrigation solution } & \multicolumn{2}{|c}{ Self-adhesive resin cement } \\
\cline { 2 - 3 } & Unicem & BisCem \\
\hline None (control) & $6.6(2.4)^{\mathrm{A}, \mathrm{a}}$ & $4.4(1.9)^{\mathrm{B}, \mathrm{bc}}$ \\
\hline $5 \% \mathrm{NaOCl}$ & $6.0(2.8)^{\mathrm{A}, \mathrm{a}}$ & $5.3(2.0)^{\mathrm{A}, \mathrm{b}}$ \\
\hline $11.5 \%$ polyacrylic acid & $6.1(3.3)^{\mathrm{A}, \mathrm{a}}$ & $3.6(1.1)^{\mathrm{B}, \mathrm{c}}$ \\
\hline $17 \%$ EDTA & $4.1(1.3)^{\mathrm{B}, \mathrm{b}}$ & $6.0(3.4)^{\mathrm{A}, \mathrm{a}}$ \\
\hline
\end{tabular}

Distinct uppercase letters in the same line indicate differences between materials; distinct lowercase letters in the same column indicate differences between treatments $(P<0.05)$.

terial). All pairwise multiple comparison procedures were carried out using Student-Newman-Keuls' method (5\% significance level).

\section{Results}

Results for bond strength are shown in Table 2. Values are reported independent of the apical third because no significant differences were observed between root portions for any group. The factor "dentin treatment" was not significant $(P=0.143)$, whereas the factor "material" $(P=0.021)$ and the interaction between the two factors $(P<0.001)$ were both significant. For Unicem, the group treated with EDTA showed significantly lower bond strength 
than the other solutions $(P \leq 0.01)$, which had similar results $(P \geq 0.345)$. For BisCem, the group treated with EDTA showed significantly higher bond strength than the other treatments $(P \leq 0.028)$. Application of $\mathrm{NaOCl}$ yielded higher bond strength for BisCem compared with that of polyacrylic acid $(P=0.026)$, whereas the control group had intermediate results.

\section{Discussion}

Both SARCs evaluated in this study have $\mathrm{pH}$ values of around $2,{ }^{17}$ which is similar to that of mild self-etch adhesives. Based on that, similar behavior was expected for both materials. However, the dentin pretreatment showed distinct effects depending on the SARC. In the present study, treating the dentin with EDTA before use of BisCem was the only treatment effective in improving the bond strength of the posts luted with SARCs. Interestingly, the use of EDTA reduced the push-out bond strength when the posts were luted with the other cement, Unicem. Reduced bond strength was also detected when polyacrylic acid was applied before BisCem. Thus, the test hypothesis was rejected. Several studies have demonstrated the limited ability of SARCs to demineralize or dissolve the smear layer to reach the underlying dentin. ${ }^{10,14,15}$ This limitation is attributed to the high viscosity of these cements and the buffering effect that takes place during their setting reaction. ${ }^{6,18}$ During posthole preparation, the intraradicular smear layer formed was thicker than those observed in coronal cavities. ${ }^{10,16}$ This thicker smear layer might hinder the interaction between the SARCs and underlying dentin.

Acid solutions, namely EDTA and polyacrylic acid, were used to irrigate the intraradicular dentin before application of the SARCs, in an endeavor to remove the smear layer and enhance contact of the SARCs with dentin. Previous studies have demonstrated that the smear layer can be partially or fully removed by all solutions used in this study in the concentrations and times employed herein. ${ }^{15,19-21}$ Thus, one could expect better interaction between the SARCs and root dentin, leading to increased bond strength, which generally did not occur. The manufacturer of Unicem recommends the use of
$2.5 \%$ to $5 \% \mathrm{NaOCl}$ solution before cementing fiber posts. However, the use of $\mathrm{NaOCl}$ did not improve post retention for any of the SARCs evaluated. Irrigation with $\mathrm{NaOCl}$ partially removes the smear layer; ${ }^{16}$ however, this agent also causes dentin deproteinization, creating a hydrophilic surface that may hinder the interaction of more hydrophobic materials such as SARCs. ${ }^{22}$ In addition, $\mathrm{NaOCl}$ has been reported to impair proper polymerization of resinbased cements. ${ }^{23}$ With that in mind, we believe that the possible improved interaction of SARCs to $\mathrm{NaO}$ $\mathrm{Cl}$-treated dentin due to removal of the smear layer may be jeopardized by less wetting of the material on the substrate and poorer cement polymerization.

EDTA is commonly used to remove the smear layer after endodontic treatment. The solution reacts with the calcium ions in dentin and forms water soluble calcium chelates. ${ }^{24}$ Irrigation using EDTA increased the push-out bond strength when BisCem was used, but reduced the retention of posts luted with Unicem. The distinct results observed for these two materials may be related to their distinct viscosity and, as a consequence, different bonding mechanisms. Apart from the effect of smear layer removal, it has been demonstrated that EDTA might additionally demineralize dentin. ${ }^{24}$ SARCs bond to dentin by a combination of chemical reaction with hydroxyapatite and penetration of resin monomers into the demineralized substrate. Thus, one could assume that SARCs having a higher potential to chemically react with the dentin may have their bonding mechanism impaired by the presence of a partially apatite-depleted substrate (caused by EDTA). In contrast, the smear layer removal and partial dentin demineralization caused by EDTA would favor the bonding of cements that rely mainly on the penetration of resin monomers. Based on that, it is reasonable to believe that Unicem presents higher chemical bonding potential, while BisCem presents higher ability to create a hybrid layer. Thus, the demineralization promoted by EDTA decreased the bonding ability of Unicem, whereas smear layer removal by EDTA probably improved the dentin infiltration of Biscem.

The use of polyacrylic acid did not affect the push-out bond strength of any of the SARCs evaluated, which showed values similar to those of the 
control group. Previous studies have shown the presence of opened dentin tubules and maintenance of mineral components in the intertubular dentin after application of polyacrylic acid. ${ }^{14,25}$ Despite this favorable scenario, penetration into the tubules can be restricted by the high viscosity of the cements. Furthermore, the opened tubules increase dentin permeability; water entering the root canal space has been demonstrated to occur even in in vitro studies. ${ }^{26}$ Thus, the presence of water can interfere with proper polymerization of the cement and reduce any positive effect obtained by improving the contact between the cement and the dentin. This detrimental effect of water can be more significant to HEMAcontaining cements such as BisCem. Resin infiltration into demineralized dentin can be promoted by HEMA, a water-soluble molecule that also attracts water, ${ }^{27}$ leading to poor polymerization and jeopardy to the bonding performance. In the present study, pretreatment with polyacrylic acid promoted the lowest values of bond strength for BisCem.

A relatively high variability in bond strength results was observed in some groups. This finding might be ascribed to differences in the degree of $\mathrm{C}=\mathrm{C}$ conversion of the cements in the various depths of the root canal. It has been shown that dual-cured SARCs might present low conversion in the absence of light activation. ${ }^{28}$ During post cementation, exposed marginal areas can greatly benefit from photoactivation, whereas light irradiance may significantly decrease toward the apical portions of the root canal due to reflecting and scattering effects. ${ }^{29}$ Lower conversion in the deeper root areas have been associated with lower bonding potential. ${ }^{5,30}$

\section{References}

1. Naumann M, Koelpin M, Beuer F, Meyer-Lueckel H. 10-year survival evaluation for glass-fiber-supported postendodontic restoration: A prospective observational clinical study. J Endod. 2012 Apr;38(4):432-5.

2. Newman MP, Yaman P, Dennison J, Rafter M, Billy E. Fracture resistance of endodontically treated teeth restored with composite posts. J Prosthet Dent. 2003 Apr;89(4):360-7.

3. Barjau-Escribano A, Sancho-Bru JL, Forner-Navarro L, Rodríguez-Cervantes PJ, Pérez-Gonzáles A, Sánchez-Marin FT. Influence of prefabricated post material on restored
No significant differences were, however, observed between the apical third for any group (data not shown). This indicates that, despite the effect monomer conversion might have on the bonding ability of SARCs, push-out bond strength tests might not be able to detect such differences.

The outcome of the present study indicates that the effect of previous dentin treatment on the pushout bond strength of SARCs to intraradicular dentin is material-dependent. Compared with the control, none of the treatments evaluated was able to improve post retention when Unicem was used, and only the use of EDTA improved the retention of posts luted with BisCem. Considering that only two SARCs were evaluated and that one type of root canal irrigation reduces post retention, there is not enough evidence to recommend any preliminary irrigation protocol when SARCs are used to lute fiber posts.

\section{Conclusions}

Within the limitations of this study, the following conclusions can be drawn:

- The only dentin pretreatment that affected the retention of posts luted with Unicem was that performed with EDTA.

- BisCem was the only material in which the dentin pretreatment with EDTA improved the bond strength to root dentin.

\section{Acknowledgements}

This study was supported by CNPq (Brazilian National Council for Scientific and Technological Development), grant \# 472216/2010-4.

teeth: Fracture strength and stress distribution. Oper Dent. 2006 Jan-Feb;31(1):47-54.

4. Amaral M, Rippe MP, Bergoli CD, Monaco C, Valandro LF. Multi-step adhesive cementation versus one-step adhesive cementation: Push-out bond strength between fiber post and root dentin before and after mechanical cycling. Gen Dent. 2011 Sep-Oct;59(5):e185-91.

5. Faria-e-Silva AL, Casselli DS, Ambrosano GM, Martins LR. Effect of the adhesive application mode and fiber post trans- 
lucency on the push-out bond strength to dentin. J Endod. 2007 Sep;33(9):1078-81.

6. Ferracane JL, Stansbury JW, Burke FJ. Self-adhesive resin cements - chemistry, properties and clinical considerations. J Oral Rehabil. 2011 Apr;38(4):295-314.

7. Gerth HUB, Dammaschke T, Zuchner H, Schafer E. Chemical analysis and bonding reaction of RelyX Unicem and Bifix composites - a comparative study. Dent Mater. 2006 Oct;22(10):934-41.

8. Al-Assaf K, Chakmakchi M, Palaghias G, Karanika-Kouma A, Eliades G. Interfacial characteristics of adhesive luting resins and composites with dentine. Dent Mater. 2007 Jul;23(7):82939.

9. Monticelli F, Osorio R, Mazzitelli C, Ferrari M, Toledano M. Limited decalcification/diffusion of self-adhesive cements into dentin. J Dent Res. 2008 Oct;87(10):974-9.

10. Barcellos DC, Batista GR, Silva MA, Rangel PM, Torres CR, Fava M. Evaluation of bond strength of self-adhesive cements to dentin with or without application of adhesive systems. J Adhes Dent. 2011 Jun;13(3):261-5.

11. Brunzel S, Yang B, Wolfart S, Kern M. Tensile bond strength of a so-called self-adhesive luting resin cement to dentin. J Adhes Dent. 2010 Apr;12(2):143-50.

12. Pavan S, Santos PH, Berger S, Bedran-Russo AK. The effect of dentin pretreatment on the microtensile bond strength of selfadhesive resin cements. J Prosthet Dent. 2010 Oct;104(4):25864.

13. Pisani-Proença J, Erhardt MC, Amaral R, Valandro LF, Bottino MA, Del Castillo-Salmerón R. Influence of different surface conditioning protocols on microtensile bond strength of self-adhesive resin cements to dentin. J Prosthet Dent. 2011 Apr;105(4):227-35.

14. Santos MJ, Bapoo H, Rizkalla AS, Santos GC. Effect of dentin-cleaning techniques on the shear bond strength of self-adhesive resin luting cement to dentin. Oper Dent. 2011 Sep-Oct;36(5):512-20.

15. Medici MC, Fröner IC. A scanning electron microscopic evaluation of different root canal irrigation regimens. Braz Oral Res. 2006 Jul-Sep;20(3):235-40.

16. Gu XH, Mao CY, Liang C, Wang HM, Kern M. Does endodontic post space irrigation affect smear layer removal and bonding effectiveness?. Eur J Oral Sci. 2009 Oct;117(5):597-603.

17. Mazzitelli C, Monticelli F, Osorio R, Casucci A, Toledano M, Ferrari M. Effect of simulated pulpal pressure on self-adhesive cements bonding to dentin. Dent Mater. 2008 Sep;24(9):115663.
18. De Munck J, Vargas M, Van Landuyt K, Hikita K, Lambrechts P, Van Meerbeek B. Bonding of an auto-adhesive luting material to enamel and dentin. Dent Mater. 2004 Dec;20(10):963-71.

19. Mazzitelli C, Monticelli F, Toledano M, Ferrari M, Osorio R. Dentin treatment effects on the bonding performance of selfadhesive resin cements. Eur J Oral Sci. 2010 Feb;118(1):80-6.

20. Kara Tuncer A, Tuncer S. Effect of different final irrigation solutions on dentinal tubule penetration depth and percentage of root canal sealer. J Endod. 2012 Jun;38(6):860-3.

21. Assis DF, Prado M, Simão RA. Evaluation of the interaction between endodontic sealers and dentin treated with different irrigant solutions. J Endod. 2011 Nov;37(11):1550-2.

22. Qian W, Shen Y, Haapasalo M. Quantitative analysis of the effect of irrigant solution sequences on dentin erosion. J Endod. 2011 Oct;37(10):1437-41.

23. Cunha LF, Furuse AY, Mondelli RF, Mondelli J. Compromised bond strength after root dentin deproteinization reversed with ascorbic acid. J Endod. 2010 Jan;36(1):130-4.

24. Ozdemir HO, Buzoglu HD, Calt S, Cehreli ZC, Varol E, Temel A. Chemical and ultramorphologic effects of ethylenediaminetetraacetic acid and sodium hypochlorite in young and old root canal dentin. J Endod. 2012 Feb;38(2):204-8.

25. Raggio DP, Sônego FG, Camargo LB, Marquezan M, Imparato JC. Efficiency of different polyacrylic acid concentrations on the smear layer, after ART technique, by Scanning Electron Microscopy (SEM). Eur Arch Paediatr Dent. 2010 Oct;11(5):232-5.

26. Chersoni S, Acquaviva GL, Prati C, Ferrari M, Grandini S, Pashley DH, et al. In vivo fluid movement through dentin adhesives in endodontically treated teeth. J Dent Res. 2005 Mar;84(3):223-7.

27. Takahashi M, Nakajima M, Hosaka K, Ikeda M, Foxton RM, Tagami J. Long-term evaluation of water sorption and ultimate tensile strength of HEMA-containing/-free one-step self-etch adhesives. J Dent. 2011 Jul;39(7):506-12.

28. Moraes RR, Boscato N, Jardim PS, Schneider LF. Dual and self-curing potential of self-adhesive resin cements as thins films. Oper Dent. 2011 Nov-Dec;36(6):635-42.

29. Faria-e-Silva AL, Arias VG, Soares LE, Martin AA, Martins LR. Influence of fiber-post translucency on degree of conversion of a dual-cured resin cement. J Endod. 2007 Mar;33(3):303-5.

30. Faria-e-Silva AL, Mendonça AA, Garcez RM, Oliveira AS, Moreira AG, Moraes RR. Adhesion strategy and early bond strengths of glass-fiber posts luted into root canals. Braz Oral Res. 2012 Oct;26(5):485-7. 